\title{
Desigualdad en la academia: mujeres en las ciencias sociales peruanas
}

\section{María Rosa Luján Limardo' Becaria EVC-CIN (2019), UNICOM-UNLZ}

\section{Reseña de libro}

Alcazar, L. y Balarín, M. (Edts). (2018). Desigualdad en la academia: mujeres en las ciencias sociales peruanas. Lima: Grupo Sofía. ISBN: 978-612-4374-04-3, pp.: 315.

Material original autorizado para su primera publicación en el Journal de Ciencias Sociales, Revista Académica de la Facultad de Ciencias Sociales de la Universidad de Palermo.

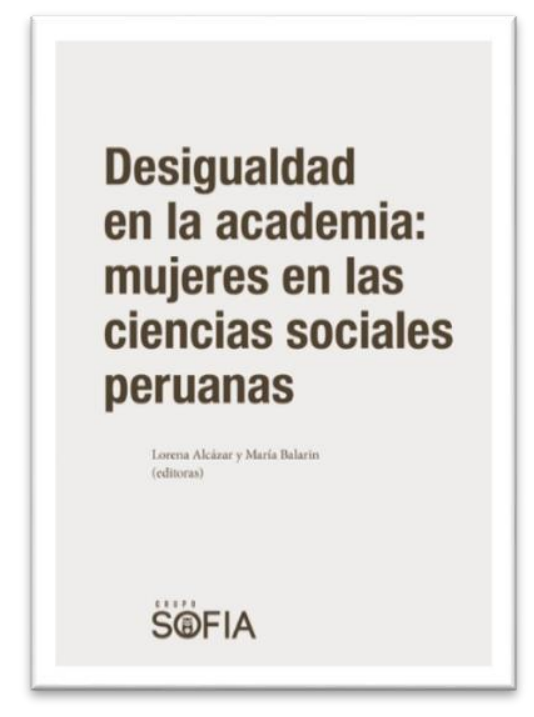

Resumen: El libro Desigualdad en la academia: mujeres en las ciencias sociales peruanas, recoge estudios de investigadoras del Grupo Sofía en torno a las desigualdades por género en el mundo de la investigación y de la docencia universitaria en las ciencias sociales. los diferentes capítulos de esta edición recorren las prácticas y usanzas de discriminación presentes en las instituciones de educación superior e investigación, referidas a las distintas formas de valorar el trabajo, considerando el impacto de esta realidad en la división por género de tareas domésticas y en mismo desarrollo profesional de las personas dedicadas a la labor académica o de investigación.

Conformado por ocho capítulos, el libro que aquí se reseña reúne aportes de un numeroso grupo de investigadoras que fueran reunidas por el Grupo Lima para esta singular

\footnotetext{
${ }^{1}$ Estudiante de la carrear de Relaciones Laborales, Facultad de Ciencias Sociales, Universidad Nacional de Lomas de Zamora (UNLZ), Argentina. Becaria EVC-CIN 2019, radicada en el Instituto de Estudios SocialesUNICOM de la UNLZ. Correo electrónico: mrllimardo@gmail.com
} 
edición. Ellas son: Patricia Ames, Norma Correa, Erika Busse, Roxana Barrantes, Patricia Ruiz-Bravo, Yamilé Guibert, Andrea Román, Karen Espinoza y María Fernanda Rodríguez. El libro recoge estudios de investigadoras del Grupo Sofía en torno a las desigualdades entre mujeres y hombres en el mundo de la investigación y de la docencia universitaria en las ciencias sociales.

El Grupo Sofía fue fundado en 2014 por una red de mujeres profesionales en Ciencias Sociales con el objetivo de intervenir en las problemáticas de género dentro de la academia del Perú, y así promover una mayor participación de las mujeres en los debates teóricos de sus disciplinas, en la producción y difusión del conocimiento, y en la formulación de políticas públicas. El Grupo Sofía cuenta con el apoyo de la Pontifica Universidad Católica del Perú (PUCP), la Universidad del Pacífico (UP), el Instituto de Estudios Peruanos (IEP) y el Grupo de Análisis para el Desarrollo (GRADE).

Desigualdad en la academia: mujeres en las ciencias sociales peruanas, es una propuesta de lectura y debate que ofrece el Grupo Sofía a partir de una recopilación de investigaciones llevadas a cabo desde diversas estrategias metodológicas (análisis documental, distribución de encuestas, desarrollo de historias de vida, etc.) a través de las cuales se presenta una serie de aristas desde donde analizar las disparidades que evidencian hombres y mujeres en sus experiencias y trayectorias laborales dentro de las Ciencias Sociales peruanas. El libro, editado por Alcazar y Balarín, busca exhibir -principalmenteaquellas barreras y oportunidades que aparecen dentro de cada grupo según su género.

Frente a lo antes expuesto, puede evidenciarse que en las trayectorias académicas las mujeres parecen encontrarse con "cañerías con fuga" y "techos de cristal"; es decir, en el caso de la primera metáfora, las mujeres "conforme pasan etapa de consolidación profesional, (...) poco a poco van quedando rezagadas". El segundo fenómeno, en tanto, da cuenta de las dificultades con la que se encuentran las mujeres durante el ascenso a los puestos de liderazgo (o a las funciones de mayor jerarquía) dentro de la carrera académica.

Interesa también descubrir qué mecanismos se ocultan detrás de esta construcción desigual que termina siendo naturalizada y que repercute en menos espacios y puestos ocupados, así como también en menores ingresos económicos percibidos, poca visibilidad y escaso poder. En este sentido, la academia parece propiciar regímenes de inequidad que, por un lado, son el reflejo de las desigualdades propias de la sociedad -de la cuales le es imposible escindirse- y que, por otro lado, forman parte de los factores extra institucionales que colaboran con la inequidad y la desigual división del trabajo doméstico (históricamente vinculadas a lo femenino), que condena a las mujeres una (cuasi) doble jornada laboral. 
El libro, además, explora la influencia de los procesos de socialización temprana que fomentan ciertas áreas de trabajo destinadas específicamente a mujeres y varones, las que repercuten en su autoconfianza, motivación y aspiraciones personales. Asimismo, el texto avanza sobre los mecanismos sutiles de discriminación en el entorno laboral que se basan en estereotipos de género con implicancias perversas en lo que respecta a la valoración personal de los sujetos, en primera persona, así como también de sus producciones científico-académicas.

Una de las investigaciones presentes en el libro que aquí se reseña, estudia -a través de entrevistas en profundidad- las trayectorias de vida de mujeres de distintas edades que han alcanzado altos cargos en la academia. Se observa, como resultado, entre otras cosas, cómo las mujeres más jóvenes postergan la maternidad para poder estudiar posgrados -que son cada vez más requeridos en mercado laboral- e intentan evitar la las "penalidades" asociadas con su decisión prematura de convertirse en madres.

Por otra parte, si bien se reconoce un indudable aumento de la participación femenina en la academia, ellas aparecen sub-representadas en los cargos docentes y superiores. En este sentido, las autoras plantean que se vuelve indispensable comenzar a revisar las efectivas oportunidades de las que disponen las mujeres para alcanzar lugares de relevancia entre los escalafones superiores como forma alternativa de atender, solamente, la igualdad de resultados en comparación con los varones. Prestar atención al modo en que las mujeres logran desarrollarse, equitativamente, con sus pares masculinos puede ser una alternativa más sofisticada, y justa, desde donde estudiar la realidad de la labor académica.

En este sentido, y en vistas a combatir la desigualdad, el libro propone llevar a cabo acciones orientadas a cerrar brechas entre hombres y mujeres, combatir estereotipos, y esforzarse por una efectiva conciliación de la vida privada y laboral. La compatibilización de la maternidad con los hitos académicos y la eliminación de toda forma de violencia sobre las mujeres, pueden ser ejemplos concretos desde donde arrancar. El despliegue de espacios de mentoría, la constitución de grupos de investigación y el trabajo de activismo coordinado son algunas de las estrategias sugeridas en el volumen.

Los arduos esfuerzos del Grupo Sofía -en materia tanto de investigación como de desarrollo- para hacer evidentes las desigualdades que enfrentan las mujeres en la academia, han permitido poner sobre el tapete la necesidad de fomentar acciones políticas para combatir este flagelo, no solamente en Perú, sino en gran parte de toda América Latina. Al ser francamente imposible escindirse de las desigualdades propias de la sociedad, la academia se convierte en un claro reflejo de ellas. Los hallazgos compartidos en el libro que aquí se reseña, permiten reflexionar sobre las desigualdades que enfrentan cotidianamente las mujeres, así como también acerca de la variabilidad de modos en que las mujeres son 
afectadas por cuestiones de género, pues las diversas formas de discriminación pueden profundizarse cuando se combina con otros factores proclives a ser causa de segregación como pueden ser: la clase social, la etnia, o la procedencia geográfica.

Como conclusión, vale la decir que se vuelve fundamental, en regiones como la latinoamericana, dedicarse a la construcción de oportunidades equitativas, que permitan una mayor riqueza de puntos de vista para alcanzar sociedades y academias más diversas y justas. Los techos de cristal que encorsetan a las mujeres podrán -finalmente- quebrarse, solo si logran llevarse a cabo profundas transformaciones culturales de manera estructura. Durante ese proceso, un rol protagónico de las mujeres será clave. 